\title{
Digesta retention patterns of solute and different-sized particles in camelids compared with ruminants and other foregut fermenters
}

\author{
Marie T. Dittmann ${ }^{1,2} \cdot$ Ullrich Runge $^{3} \cdot$ Sylvia Ortmann ${ }^{4} \cdot$ Richard A. Lang $^{5} \cdot$ \\ Dario Moser ${ }^{6}$ - Cordula Galeffi ${ }^{7}$ Angela Schwarm ${ }^{2} \cdot$ Michael Kreuzer $^{2}$ • \\ Marcus Clauss ${ }^{1}$
}

Received: 12 February 2015 / Revised: 6 April 2015 / Accepted: 19 April 2015 / Published online: 29 April 2015

(C) Springer-Verlag Berlin Heidelberg 2015

\begin{abstract}
The mean retention times (MRT) of solute or particles in the gastrointestinal tract and the forestomach (FS) are crucial determinants of digestive physiology in herbivores. Besides ruminants, camelids are the only herbivores that have evolved rumination as an obligatory physiological process consisting of repeated mastication of large food particles, which requires a particle sorting mechanism in the FS. Differences between camelids and ruminants have hardly been investigated so far. In this study we measured MRTs of solute and differently sized particles $(2,10$, and $20 \mathrm{~mm}$ ) and the ratio of large-to-small particle MRT, i.e. the selectivity factors $\left(\mathrm{SF}_{10 / 2 \mathrm{~mm}}, \mathrm{SF}_{20 / 2 \mathrm{~mm}}, \mathrm{SF}_{20 / 10 \mathrm{~mm}}\right)$, in three camelid species: alpacas (Vicugna pacos), llamas (Llama glama), and Bactrian camels (Camelus bactrianus). The camelid data were compared with literature data from ruminants and non-ruminant foregut fermenters (NRFF). Camelids and ruminants both had higher $\mathrm{SF}_{10 / 2 \mathrm{~mm}} \mathrm{FS}$ than NRFF, suggesting convergence in the function of the FS
\end{abstract}

Communicated by I. D. Hume.

Marcus Clauss

mclauss@vetclinics.uzh.ch

1 Clinic for Zoo Animals, Exotic Pets and Wildlife, Vetsuisse Faculty Zurich, University of Zurich, Winterthurerstr. 260, 8057 Zurich, Switzerland

2 ETH Zurich, Institute of Agricultural Sciences, Zurich, Switzerland

3 Kamelhof Olmerswil, Neukirch/Thur, Switzerland

4 Leibniz Institute for Zoo and Wildlife Research (IZW), Berlin, Germany

5 Cochranton Veterinary Hospital, Cochranton, PA, USA

6 Zoological Institute, University of Basel, Basel, Switzerland

7 Zurich Zoo, Zurich, Switzerland sorting mechanism in contrast to NRFF, in which such a sorting mechanism is absent. The $\mathrm{SF}_{20 / 10 \mathrm{~mm}} \mathrm{FS}$ did not differ between ruminants and camelids, indicating that there is a particle size threshold of about $1 \mathrm{~cm}$ in both suborders above which particle retention is not increased. Camelids did not differ from ruminants in $\mathrm{MRT}_{2 \mathrm{~mm}} \mathrm{FS}, \mathrm{MRT}_{\text {solute }} \mathrm{FS}$, and the ratio $\mathrm{MRT}_{2 \mathrm{~mm}} \mathrm{FS} / \mathrm{MRT}_{\text {solute }} \mathrm{FS}$, but they were more similar to 'cattle-' than to 'moose-type' ruminants. Camelids had higher $\mathrm{SF}_{10 / 2 \mathrm{~mm}} \mathrm{FS}$ and higher $\mathrm{SF}_{20 / 2 \mathrm{~mm}} \mathrm{FS}$ than ruminants, indicating a potentially slower particle sorting in camelids than in ruminants, with larger particles being retained longer in relation to small particles.

Keyword Digesta kinetics - Digesta passage - Rumen · Digesta washing $\cdot$ Selectivity factor

\section{Introduction}

The digestive strategy of non-ruminant foregut fermenters has historically been considered 'ruminant-like' (e.g. Moir et al. 1954; Bauchop and Martucci 1968), but the process of rumination clearly sets ruminants apart from non-ruminant foregut fermenters (Fritz et al. 2009; Schwarm et al. 2009b; Clauss et al. 2010). True rumination has evolved in only two artiodactyl lineages, the ruminants and the camelids, while sporadic regurgitation and repeated mastication of stomach contents (merycism) have been reported in a variety of mammals such as koala (Phascolarctos cinereus) (Logan 2001, 2003), macropods (Moir et al. 1956; Mollison 1960; Barker et al. 1963; Hendrichs 1965), hyrax (Procavia capensis) (Hendrichs 1965), capybara (Hydrochoerus hydrochaeris) (Lord 1994), and proboscis monkeys (Nasalis larvatus) (Matsuda et al. 2011, 2014). In contrast to merycism, rumination is an obligatory, regular behavioural 


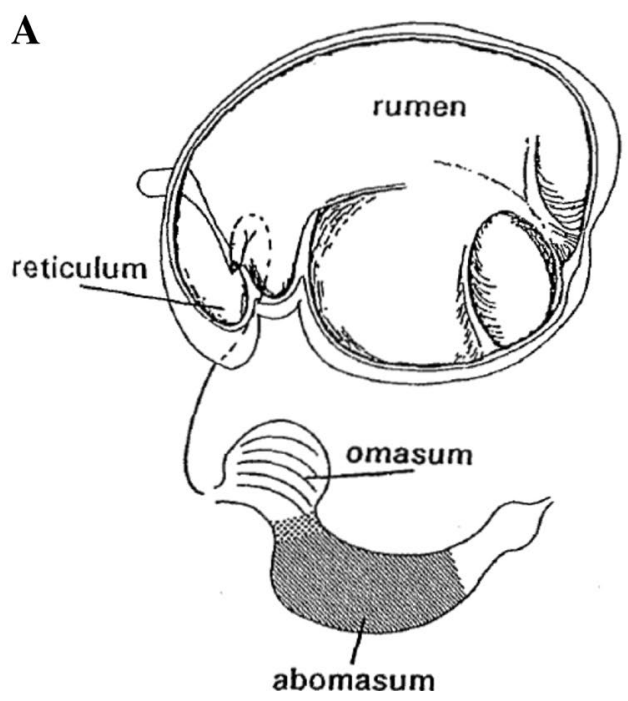

Fig. 1 Schematic comparison of the morphology of the forestomach complex (viewed from its left side, with parts that cannot be viewed from the left displaced underneath) in a ruminants and $\mathbf{b}$ camelids (Lechner-Doll et al. 1995). The ruminant forestomach consists of the rumen (with various sub-compartments), the reticulum, the omasum and the abomasum. The reticulum and omasum are linked by the reticulo-omasal orifice. The camelid forestomach consists of the first compartment $(\mathrm{C} 1$, with a cranial and a caudal sub-compartment and typical 'glandular sacs'), the second compartment (C2, also some-

and physiological process (Gordon 1968) that is characterised not only by 'repeated mastication' but also by a density-dependent sorting mechanism in the forestomach (FS) of ruminants and camelids (Lechner-Doll et al. 1991). This mechanism is absent in non-ruminant foregut fermenters (Schwarm et al. 2008, 2009c, 2013). In ruminants and camelids, this mechanism ensures that only those particles are ruminated that require further comminution.

While camelids and ruminants both ruminate, several differences set these groups apart: different chewing motions during rumination (Hendrichs 1965), the different design of the FS (Langer 1988) (Fig. 1), and different FS motility patterns (Heller et al. 1984, 1986b). More generally, camelids have a lower metabolic rate (measured, e.g. via oxygen consumption) and a lower food intake than ruminants of comparable body size (Dittmann et al. 2014a). The latter aspect might be related to the longer digesta retention times found in camelids (Heller et al. 1986c). In ruminants, the reticulo-omasal orifice represents a clear demarcation line before which particle sorting takes place in the reticulum, and beyond which only small particles are found (Clauss et al. 2009a, b). In camelids, particle sorting takes place in compartment $\mathrm{C} 2$ that is sometimes also referred to as a 'reticulum' (Langer 1988). The connection between the $\mathrm{C} 2$ ('reticulum') and the $\mathrm{C} 3$ (the 'gastric tube') is not an orifice but a short tubular canal (Vallenas et al. 1971; Langer 1988). Potentially, this canal does not

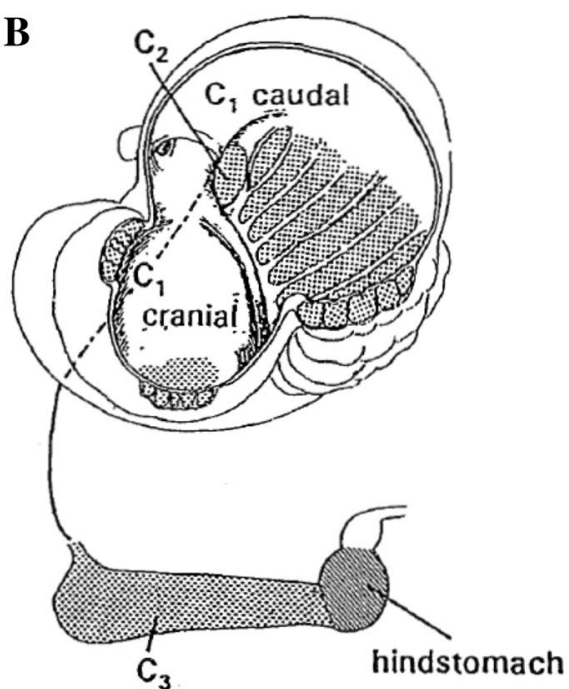

times referred to as the 'reticulum', also containing 'glandular sacs') and a third compartment (C3, consisting of a cranial part and a caudal 'hindstomach'). The $\mathrm{C} 2$ and the $\mathrm{C} 3$ are linked by a small tubular canal. White surfaces represent a stratified epithelium (in the case of ruminants, with papillae in the rumen and the typical honeycomb cells in the reticulum), dotted areas represent cardiac glands (covering the 'glandular sacs' and the cranial portion of C3), and striped areas represent acid-secreting glandular stomach epithelium

represent as clear a point of demarcation as the reticuloomasal orifice in ruminants, because large particles have been found beyond this point in the proximal part of the third compartment (Lechner-Doll and von Engelhardt 1989). These large particles are presumably transported backwards into the $\mathrm{C} 2$. Hence, it has been suggested that the sorting mechanism in the FS of camelids is less efficient than in ruminants and that the emptying of the FS is too slow to allow similarly high relative food intakes as those observed in some ruminant species (Clauss et al. 2010). The retention of solute as well as small and large particle markers has been investigated in camelids (Heller et al. 1986a, c; Lechner-Doll et al. 1990; Cahill and McBride 1995; von Engelhardt et al. 2006b), and a sorting mechanism in the FS, as reflected by longer retention of larger as compared with smaller particles, has been demonstrated (Heller et al. 1986a, c; Lechner-Doll et al. 1990). So far, comparative studies of retention times in ruminants and camelids are lacking. In ruminants, marked differences between species occur with respect to the retention of solute and particle markers (Dittmann et al. 2015). The efficacy of the ruminant sorting mechanism, however, is not affected by such species differences (Lechner et al. 2010). Furthermore, while the sorting mechanism of ruminants differentiates between small $(<2 \mathrm{~mm})$ and larger $(10 \mathrm{~mm})$ particles, it does not further differentiate between large particle-size classes (10 vs. $20 \mathrm{~mm}$ ) (Schwarm et al. 2009a; 
Lechner et al. 2010). To our knowledge, it has not yet been investigated whether the sorting mechanism in the FS of camelids is not only qualitatively, but also quantitatively similar to that in ruminants.

The aim of this study was to assess the retention patterns of solutes and differently sized particles in three camelid species, to compare retention times and the sorting mechanism within camelids, and with ruminants and non-ruminant foregut fermenters.

\section{Methods}

\section{Animals and husbandry}

The measurements were approved by the Cantonal Veterinary Office Zurich and took place under the Swiss Cantonal Animal Experiment Licence no. 142/2011 in the framework of a comprehensive experiment using respiration chambers to determine metabolic rates (Dittmann et al. 2014a) and methane production (Dittmann et al. 2014b) in three camelid species. All experimental animals were adult and included representatives of Bactrian camels (Camelus bactrianus, $n=5$ ) and llamas (Lama glama, $n=6$ ) kept on a private farm in Switzerland, and alpacas (Vicugna pacos, $n=5$ ) kept at Zurich Zoo. Prior to the experiment the animals were acclimated to a diet consisting of lucerne hay provided ad libitum and a limited amount of lucerne pellets (for a detailed nutrient analysis of diets, see Dittmann et al. 2014b). The pellets eventually made up 53, 33, and $21 \%$ of total dry matter intake (DMI) in alpacas, llamas and Bactrian camels, respectively. In order to ensure comparable ad libitum intakes in all species, alpacas received a higher proportion of pellets because the voluntary daily intake of lucerne hay (per unit metabolic body mass) was comparably low in this species. All animals were weighed prior to the experiment. During the experiment, the animals were kept individually on the same diet in separate adjacent indoor pens that allowed visual and acoustic contact. Food intake was determined by weighing diet items offered and the corresponding refusals several times per day for 6-7 days. Representative samples of food and refusals were taken and dried at $60{ }^{\circ} \mathrm{C}$. Dry matter (DM) content was analysed by drying at $103{ }^{\circ} \mathrm{C}$ following AOAC no. 942.05 (AOAC 1995). Pens were cleaned on daily basis and animals had unrestricted access to water.

\section{Determination of solute and particle retention times}

The principle of mean retention time (MRT) measurement is the application (typically as a single pulse-dose) of a non-absorbable marker, the excretion of which over time is then detected by analysing faecal samples for the marker concentration (Warner 1981). To measure MRT of particles and fluid, four markers from the same batch as those used by Lechner et al. (2010) were fed, which are considered representative of four different digesta components: three different sized particle markers based on fibre from grass hay mordanted with Chromium $(\mathrm{Cr} ;<2 \mathrm{~mm})$, Cerium (Ce; approx. $10 \mathrm{~mm}$ ), Lanthanum (La; approx. $20 \mathrm{~mm}$ ), and Cobalt ethylene diaminetetracetic acid (Co-EDTA; soluble in water). Markers were prepared according to Udén et al. (1980) and Schwarm et al. (2008, 2009a). Bactrian camels and llamas received all four markers, while alpacas received only $\mathrm{Cr}$ - and Ce-mordanted fibres and Co-EDTA; based on our observations of the feeding behaviour of the latter species, we expected reluctance of marker ingestion if too much marker material would have been offered. Prior to the administration of the markers, three faecal samples were collected to determine baseline marker concentrations in each animal. Individuals were then fed the particle markers at $0.1 \mathrm{~g} \mathrm{~kg}^{-1}$ body mass (BM) each and CoEDTA at $0.01 \mathrm{~g} \mathrm{~kg}^{-1} \mathrm{BM}$ dissolved in water. Markers were fed in mixture with a small amount of lucerne pellets and were consumed within approximately $30 \mathrm{~min}$. The time when the animals had completely ingested the markers was considered $0 \mathrm{~h}$, after which faeces of llamas and Bactrian camels were sampled every $4 \mathrm{~h}$ for the first $60-84 \mathrm{~h}$ after marker application and every $6 \mathrm{~h}$ for the remaining time of the 7 days. Faeces of alpacas were sampled every $4 \mathrm{~h}$ for the first 2 days after marker application, every $6 \mathrm{~h}$ on day 3 , every $8 \mathrm{~h}$ on day 4 , and every $12 \mathrm{~h}$ on days 5,6 , and 7 . Due to differences in facilities and husbandry between species, the sampling protocol differed between species. However, the method used for calculating retention times was independent of sampling intervals, as demonstrated by Van Weyenberg et al. (2006). All samples were immediately ovendried at $60{ }^{\circ} \mathrm{C}$ and later ground to $0.75 \mathrm{~mm}$. Marker analysis was performed in a similar way as in previous studies (Frei et al. 2015). For wet ashing we heated samples with $4 \mathrm{ml}$ nitric acid $\left(\mathrm{HNO}_{3}\right)$ and $2 \mathrm{ml}$ hydrogen peroxide with the microwave MLS 'START 1500' (MLS GmbH, Leutkich, Germany). Temperature was increased over $15 \mathrm{~min}$ to $170{ }^{\circ} \mathrm{C}$, and over $20 \mathrm{~min}$ to $200{ }^{\circ} \mathrm{C}$, and then held at $200{ }^{\circ} \mathrm{C}$ for $5 \mathrm{~min}$. The wave-length was $12.25 \mathrm{~cm}$ and the frequency $2.45 \mathrm{GHz}$. Determination of $\mathrm{Co}, \mathrm{Cr}, \mathrm{Ce}$, and $\mathrm{La}$ in the sample digests was performed using an inductively coupled plasma optical emission spectrometer (model Optima 8000, Perkin Elmer, Rodgau, Germany). Sample introduction was carried out using a peristaltic pump connected to a Meinhard nebulizer with a cyclon spray chamber. The measured spectral element lines were: Co: $228.616 \mathrm{~nm}$; Cr: 267.716; Ce: $413.764 \mathrm{~nm}$; La: $398.852 \mathrm{~nm}$. The RF power was set to $1400 \mathrm{~W}$, the plasma gas was $8 \mathrm{~L}$ argon $\mathrm{min}^{-1}$, whereas the nebulizer gas was $0.6 \mathrm{~L}$ argon $\mathrm{min}^{-1}$. Values were corrected for the individual baseline concentrations prior to the 
marker application. To avoid an artificial increase in MRT by infinite excretion curves due to variation in baseline concentrations, values below $1 \%$ of the maximum concentration of a marker in the excretion curve were set to zero (adapted from Bruining and Bosch 1992).

We estimated MRT in the gastrointestinal tract (GIT) by an algebraic equation, and the MRT of the solute marker in the forestomach using the descending part of the marker excretion curve, following published procedures. MRT GIT was calculated according to Thielemans et al. (1978) as

MRT GIT $=\sum\left(t_{i} \times \mathrm{d} t \times c_{i}\right) / \sum\left(\mathrm{d} t \times c_{i}\right)$,

where $t_{i}$ is a time after marker application in h determined as the midpoint between two sampling intervals, $\mathrm{d} t$ is time interval represented by the marker concentration calculated as $\left(\left(t_{i+1}-t_{i}\right)+\left(t_{i}-t_{i-1}\right)\right) / 2$, and $c_{i}$ is faecal marker concentration at $t_{\mathrm{i}}$ in $\mathrm{mg} \mathrm{kg}^{-1} \mathrm{DM}$. In contrast to equations that calculate MRT GIT without considering the time interval $\mathrm{d} t$ (Blaxter et al. 1956; Warner 1981), this equation has the advantage that the sampling frequency has no influence on the calculated MRT result (Van Weyenberg et al. 2006).

The mean retention time of the solute marker in the FS $\left(\mathrm{MRT}_{\text {solute }} \mathrm{FS}\right)$ was calculated by estimating the rate constant of the descending part of the marker excretion curve using an exponential equation according to Lechner-Doll et al. (1990) as

$y=A \times \mathrm{e}^{-k \times t}$,

where $y$ is faecal marker concentration at time $t$ in $\mathrm{mg} \mathrm{kg}^{-1}$ $\mathrm{DM}, A$ is constant, $k$ is the rate constant of the descending part of the excretion curve in $\mathrm{h}^{-1}$, and $t$ is time after marker application in h. According to Hungate (1966), the reciprocal value of $\mathrm{k}$ represents the MRT within the compartment characterised by $\mathrm{k}$. This approach, therefore, assumes that the forestomach is the major mixing compartment in the camelid GIT. Based on the assumption that fluid and particles do not differ in passage characteristics distal to the FS (empirically confirmed in ruminants by Grovum and Williams 1973; Kaske and Groth 1997; Mambrini and Peyraud 1997), $\mathrm{MRT}_{\text {particle }} \mathrm{FS}$ is calculated as

$\mathrm{MRT}_{\text {particle }} \mathrm{FS}=\mathrm{MRT}_{\text {particle }} \mathrm{GIT}-\left(\mathrm{MRT}_{\text {solute }} \mathrm{GIT}-\mathrm{MRT}_{\text {solute }} \mathrm{FS}\right)$.

The selectivity factor (SF) is defined as the ratio of two MRTs, either particle to solute or large to small particles. It was calculated for both total GIT and the FS, and for the small particle marker MRTs to solute MRT ( $\mathrm{Cr}: \mathrm{Co}$,$) , and$ for larger to smaller particle MRTs (Ce:Cr, $\mathrm{La}: \mathrm{Cr}, \mathrm{La}: \mathrm{Ce})$.

\section{Comparative literature}

Data on the retention of comparable passage markers obtained in various camelids, ruminants, and non-ruminant foregut fermenters (NRFF) were collected from the literature. Data on ruminant $\mathrm{MRT}_{2 \mathrm{~mm}}$ and $\mathrm{MRT}_{\text {solute }}$ are the same as provided in the Supplementary Table of Dittmann et al. (2015). Data sources of 10 and $20 \mathrm{~mm}$ particle markers from ruminants, camelids, and NRFF are presented in Table 1. For the dataset on $\mathrm{MRT}_{2 \mathrm{~mm}}$ and $\mathrm{MRT}_{\text {solute }}$ we classified the ruminant species as 'cattle-' or 'moose-type', based on their $\mathrm{SF}_{2 \mathrm{~mm} / \mathrm{solute}} \mathrm{FS}$ because 'cattle-type' ruminants are defined as having comparatively shorter solute retention times in the reticulorumen, and thereby higher $\mathrm{SF}_{2 \mathrm{~mm} / \mathrm{solute}} \mathrm{FS}$ values, than 'moose-type' ruminants (Clauss et al. 2010).

For NRFF, no data were available for large $(20 \mathrm{~mm})$ particle markers. Because data were available from many different species for the solute and small particle $(2 \mathrm{~mm})$ markers, the data incorporated in analyses with respect to these to markers were averaged per species. Species means for all measures were first calculated as an average per source and then as mean of all source averages. In total, we collated data from 32 ruminant species (consisting of 13 'moose' and 19 'cattle-type' species), four camelid species, and seven non-ruminant foregut fermenter species. For the datasets including 10 and $20 \mathrm{~mm}$ particle markers, fewer measurements were available and, therefore, analyses were performed with data from individual animals, not species means, and without PGLS analyses (see below).

\section{Statistical evaluation}

The relative dry matter intake (rDMI) was calculated using an exponent of $\mathrm{BM}^{0.85}$, following Müller et al. (2013). This approach was supported by the data obtained from the camelids investigated in this study, in which DMI scaled at $\mathrm{BM}^{0.85}(95 \% \mathrm{CI}: 0.75 ; 0.94)$. Data from species investigated in the present study were tested for normal distribution by applying a Shapiro-Wilk test, based on which we used ANOVAs for comparison of retention times between and within species, followed by pair-wise Tukey HSD post hoc tests. Data from Bactrian camels were compared with literature data from dromedaries (Lechner-Doll et al. 1990), by applying unpaired two tailed t-tests. All statistical tests were carried out in R 2.15.0 (R Development Core Team 2012) using the packages ape (Paradis et al. 2004), caper (Orme et al. 2010), and nlme (Pinheiro et al. 2011).

Correlations including data from species investigated in the present study and literature data from other herbivores were investigated by applying general least squares (GLS) models with MRT, SF or DMI as dependent variable and $\mathrm{BM}$ or rDMI as independent variables. In the GLS, herbivore type (camelid, ruminant [either as such or separated into 'moose-' and 'cattle-type'] or NRFF) was added as a cofactor. For each model, we tested the interaction between the independent variable and the cofactor. This interaction was removed from the model when not significant. 
Table 1 Sources for retention time measures of 2, 10 and $20 \mathrm{~mm}$ particles in ruminants, camelids and non-ruminant foregut fermenters used in the comparative evaluation (see Dittmann et al. 2015 for a complete list of ruminant species with measurements for 2 mm particles and solutes)

\begin{tabular}{|c|c|c|c|c|c|c|c|c|}
\hline Species & Herbivore type & $\mathrm{MRT}_{2 \mathrm{~mm}} \mathrm{GIT}$ & $\mathrm{MRT}_{10 \mathrm{~mm}} \mathrm{GIT}$ & $\mathrm{MRT}_{20 \mathrm{~mm}} \mathrm{GIT}$ & $\mathrm{MRT}_{2 \mathrm{~mm}} \mathrm{FS}$ & $\mathrm{MRT}_{10 \mathrm{~mm}} \mathrm{FS}$ & $\mathrm{MRT}_{20 \mathrm{~mm}} \mathrm{FS}$ & MRT sources \\
\hline $\begin{array}{l}\text { Cam. drom- } \\
\text { edarius }\end{array}$ & Camelid & $x$ & & $x$ & $x$ & & $x$ & $\begin{array}{l}\text { (Heller et al. } \\
\text { 1986c; Lechner } \\
\text { Doll et al. 1990) }\end{array}$ \\
\hline Lama glama & Camelid & $x$ & & $\times$ & $x$ & & $x$ & $\begin{array}{c}\text { (Heller et al. } \\
\text { 1986a) }\end{array}$ \\
\hline Alces alces & Ruminant & $x$ & $\times$ & $x$ & $x$ & $x$ & $x$ & $\begin{array}{l}\text { (Lechner et al. } \\
\text { 2010) }\end{array}$ \\
\hline Bos javanicus & Ruminant & $x$ & $\times$ & & $\times$ & $\times$ & & $\begin{array}{l}\text { (Schwarm et al. } \\
\text { 2008) }\end{array}$ \\
\hline Bos taurus & Ruminant & $x$ & $\times$ & $x$ & $x$ & $\times$ & $x$ & $\begin{array}{l}\text { (Lirette and } \\
\text { Milligan 1989; } \\
\text { Lechner-Doll } \\
\text { et al. 1990; } \\
\text { Lechner et al. } \\
\text { 2010) }\end{array}$ \\
\hline Capra hircus & Ruminant & $x$ & & $x$ & $\times$ & & $x$ & $\begin{array}{l}\text { (Lechner-Doll } \\
\text { et al. 1990) }\end{array}$ \\
\hline $\begin{array}{l}\text { Ovibos mos- } \\
\text { chatus }\end{array}$ & Ruminant & $x$ & $\times$ & $x$ & $\times$ & $\times$ & $x$ & $\begin{array}{l}\text { (Lechner et al. } \\
\text { 2010) }\end{array}$ \\
\hline Ovis aries & Ruminant & $x$ & & $\times$ & $\times$ & & $\times$ & $\begin{array}{l}\text { (Lechner-Doll } \\
\text { et al. 1990) }\end{array}$ \\
\hline $\begin{array}{l}\text { Rangifer taran- } \\
\quad \text { dus }\end{array}$ & Ruminant & $x$ & $\times$ & $x$ & $\times$ & $\times$ & $x$ & $\begin{array}{l}\text { (Lechner et al. } \\
\text { 2010) }\end{array}$ \\
\hline Tayassu tajacu & NRFF & $\times$ & $\times$ & & $\times$ & $\times$ & & $\begin{array}{l}\text { (Schwarm et al. } \\
2009 \text { c) }\end{array}$ \\
\hline $\begin{array}{l}\text { Hexapr. lib- } \\
\text { eriensis }\end{array}$ & NRFF & $x$ & $\times$ & & $\times$ & $\times$ & & $\begin{array}{l}\text { (Clauss et al. } \\
\text { 2004; Schwarm } \\
\text { et al. 2008) }\end{array}$ \\
\hline $\begin{array}{l}\text { Hippop. } \\
\text { amphibius }\end{array}$ & NRFF & $x$ & $x$ & & $x$ & $\times$ & & $\begin{array}{l}\text { (Clauss et al. } \\
\text { 2004) }\end{array}$ \\
\hline $\begin{array}{l}\text { Colobus ango- } \\
\text { lensis }\end{array}$ & NRFF & $\times$ & $\times$ & & $\times$ & $\times$ & & $\begin{array}{l}\text { (Schwarm et al. } \\
2009 \text { c) }\end{array}$ \\
\hline $\begin{array}{l}\text { Colobus polyko- } \\
\quad \text { mos }\end{array}$ & NRFF & $x$ & $\times$ & & $x$ & $\times$ & & $\begin{array}{l}\text { (Schwarm et al. } \\
2009 \text { c) }\end{array}$ \\
\hline Presbytis johnii & NRFF & $\times$ & $\times$ & & $\times$ & $\times$ & & $\begin{array}{l}\text { (Schwarm et al. } \\
2009 \text { c) }\end{array}$ \\
\hline Macropus rufus & NRFF & $x$ & $x$ & & $x$ & $\times$ & & $\begin{array}{l}\text { (Schwarm et al. } \\
2009 \mathrm{c})\end{array}$ \\
\hline
\end{tabular}

Different data subsets have different numbers of species depending on whether information on dry matter intake and various retention measures were available

$M R T$ mean retention time, GIT gastrointestinal tract, $F S$ forestomach, NRFF non-ruminant foregut fermenter

Additionally, to investigate differences in relationships between large and small particle markers between herbivore types, we applied GLS with large particle markers as dependent and small particle markers as independent variables, and with herbivore type as a cofactor (and interactions of the latter two). The respective SFs were tested for differences between herbivore types by applying ANOVA or Kruskal-Wallis tests, followed by Tukey HSD post hoc tests or non-parametric pair-wise tests as means for multiple comparisons (R function kruskalmc).
Species cannot be considered independent units, as they share an evolutionary history which means that similarities between species might only be an artefact of their ancestry (Felsenstein 1985). This lack of independence violates basic assumptions of many statistical tests, which is why we accounted for phylogeny by applying Phylogenetic Generalised Least Squares (PGLS) analyses. Data were linked to a supertree of extant mammals (Bininda-Emonds et al. 2007, 2008), for the same models investigated by GLS 

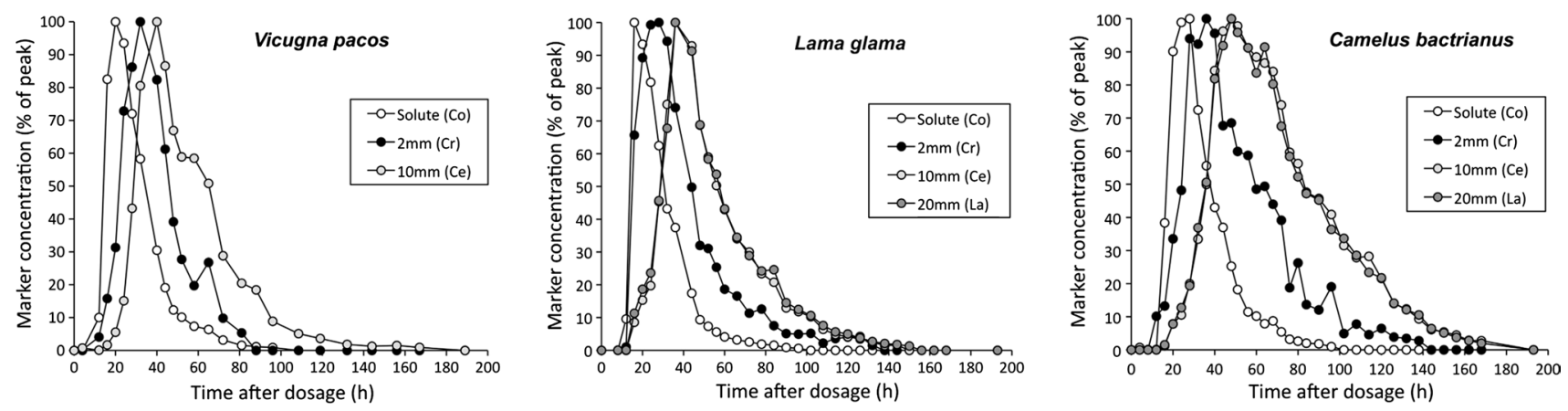

Fig. 2 Exemplary excretion curves of the solute and particle markers of each one alpaca (Vicugna pacos), llama (Llama glama) and Bactrian camel (Camelus bactrianus)

Table 2 Body mass, dry matter intake, and retention times and selectivity factors of the gastrointestinal tract from the camelids investigated in this study and from dromedaries (C. dromedarius) investigated by Lechner-Doll et al. (1990)

\begin{tabular}{|c|c|c|c|c|c|c|c|c|c|c|}
\hline \multirow[t]{2}{*}{ Species } & \multirow{2}{*}{$\begin{array}{l}\text { Body mass } \\
(\mathrm{kg})\end{array}$} & \multirow{2}{*}{$\begin{array}{l}\operatorname{rDMI}(\mathrm{g} \\
\left.\mathrm{kg}^{-0.85} \mathrm{~d}^{-1}\right)\end{array}$} & \multicolumn{4}{|c|}{ MRT GIT (h) } & \multicolumn{4}{|l|}{ SF GIT } \\
\hline & & & Solute & $2 \mathrm{~mm}$ & $10 \mathrm{~mm}$ & $20 \mathrm{~mm}$ & $2 \mathrm{~mm} /$ solute & $10 / 2 \mathrm{~mm}$ & $20 / 2 \mathrm{~mm}$ & $20 / 10 \mathrm{~mm}$ \\
\hline $\begin{array}{c}\text { Vicugna } \\
\text { pacos }\end{array}$ & $63 \pm 12$ & $34 \pm 7$ & $34 \pm 6^{1}$ & $50 \pm 12^{2}$ & $59 \pm 12^{3}$ & n.m. & $1.46 \pm 0.13$ & $1.20 \pm 0.14^{\mathrm{a}}$ & n.m. & n.m. \\
\hline Lama glama & $148 \pm 26$ & $35 \pm 5$ & $29 \pm 2^{1}$ & $40 \pm 4^{2}$ & $58 \pm 4^{3}$ & $57 \pm 3^{\mathrm{a} 3}$ & $1.40 \pm 0.09$ & $1.47 \pm 0.14^{\mathrm{b}}$ & $1.44 \pm 0.11$ & $0.98 \pm 0.03$ \\
\hline $\begin{array}{l}\text { Camelus } \\
\text { bactrianus }\end{array}$ & $658 \pm 72$ & $35 \pm 6$ & $34 \pm 3^{1}$ & $47 \pm 6^{2}$ & $66 \pm 5^{3}$ & $67 \pm 5^{\mathrm{b} 3}$ & $1.38 \pm 0.11$ & $1.42 \pm 0.07^{\mathrm{b}}$ & $1.43 \pm 0.0^{7}$ & $1.01 \pm 0.02$ \\
\hline $\begin{array}{l}\text { Camelus } \\
\text { dromedarius }\end{array}$ & $453 \pm 95$ & n.m. & $45 \pm 8^{*}$ & $61 \pm 7^{*}$ & n.m. & $88 \pm 12^{*}$ & $1.36 \pm 0.09$ & n.m. & $1.43 \pm 0.10$ & n.m. \\
\hline
\end{tabular}

Superscript letters indicate significant differences $(p<0.05)$ between MRT measures and SFs within columns, superscript numbers indicate differences of MRT or SFs within species and asterisks indicate significant differences in the respective means between $C$. bactrianus and C. dromedarius

$r D M I$ relative dry matter intake, $M R T$ mean retention time, GIT gastrointestinal tract, $S F$ selectivity factor, n.m. not measured

in the dataset for $\mathrm{MRT}_{2 \mathrm{~mm}}$ for which values of many different species were available, without the inclusion of herbivore type as a cofactor. The value of the phylogenetic signal $(\lambda)$ (Pagel 1999), which can be considered a measure of the phylogenetic structure in the dataset, was estimated with maximum likelihood (Revell 2010), using the PGLS command from the package caper (Orme et al. 2010). Additionally, Akaike's information criterion (AIC) for the models was determined using the R function AIC to determine which model has the better fit. Significance levels were set to $\alpha=0.05$, with values between 0.05 and 0.10 considered as trends.

\section{Results}

\section{Differences between camelid species}

Marker elimination curves for the three species indicated a typical sequence in marker elimination peaks, with the solute marker being eliminated first, followed by the small particle marker and then by the two large particle markers (Fig. 2). In the two species (camels and llamas) where three particle markers had been applied, the MRTs (both in GIT and FS) of the two large particle markers did not differ from each other $(P>0.99$ and $P>0.79$, respectively). All other MRTs, in GIT and FS, differed significantly between each other within each species (camels: $P<0.001$; llamas: $P<0.001$; alpacas: $P<0.023$ ) (Tables 2 and 3).

In general, there were no significant differences in retention times of the different markers between species; only llamas had shorter $\mathrm{MRT}_{20 \mathrm{~mm}}$ GIT and FS than Bactrian camels $(P<0.036) . \mathrm{SF}_{10 / 2 \mathrm{~mm}}$ GIT and FS were lower in alpacas than in llamas $(P<0.041)$ and Bactrian camels $(P<0.011)$.

Comparing our measurements of the large camelid, the Bactrian camel, to literature data from dromedaries (Lechner-Doll et al. 1990), revealed longer MRTs for all markers in the GIT $(P=0.000-0.002)$, shorter MRT $_{\text {solute }} \mathrm{FS}(P=0.002)$ and a trend towards shorter $\mathrm{MRT}_{2 \mathrm{~mm}} \mathrm{FS}(P=0.071)$ in dromedaries (Tables 2 and 3$)$. Only $\mathrm{MRT}_{20 \mathrm{~mm}} \mathrm{FS}$ did not differ between the two species 
Table 3 Retention times and selectivity factors of the forestomach from the camelids investigated in this study and from dromedaries $(C$. dromedarius) investigated in Lechner-Doll et al. (1990)

\begin{tabular}{|c|c|c|c|c|c|c|c|c|}
\hline \multirow[t]{2}{*}{ Species } & \multicolumn{4}{|c|}{ MRT FS (h) } & \multicolumn{4}{|l|}{ SF FS } \\
\hline & Solute & $2 \mathrm{~mm}$ & $10 \mathrm{~mm}$ & $20 \mathrm{~mm}$ & $2 \mathrm{~mm} /$ solute & $10 / 2 \mathrm{~mm}$ & $20 / 2 \mathrm{~mm}$ & $20 / 10 \mathrm{~mm}$ \\
\hline Vicugna pacos & $22 \pm 7^{1}$ & $38 \pm 11^{2}$ & $47 \pm 11^{3}$ & n.m. & $1.74 \pm 0.26$ & $1.28 \pm 0.22^{\mathrm{a}}$ & n.m. & n.m. \\
\hline Lama glama & $17 \pm 3^{1}$ & $28 \pm 3^{2}$ & $47 \pm 5^{3}$ & $45 \pm 4^{\mathrm{a} 3}$ & $1.71 \pm 0.23$ & $1.66 \pm 0.15^{\mathrm{b}}$ & $1.62 \pm 0.12$ & $0.97 \pm 0.05$ \\
\hline Camelus bactrianus & $19 \pm 3^{1}$ & $32 \pm 5^{2}$ & $51 \pm 4^{3}$ & $51 \pm 4^{\mathrm{b} 3}$ & $1.72 \pm 0.29$ & $1.63 \pm 0.14^{\mathrm{b}}$ & $1.64 \pm 0.11$ & $1.01 \pm 0.04$ \\
\hline Camelus dromedarius & $11 \pm 1^{*}$ & $26 \pm 3^{(*)}$ & n.m. & $53 \pm 7$ & $2.52 \pm 0.31 *$ & n.m. & $2.01 \pm 0.30^{*}$ & n.m. \\
\hline
\end{tabular}

Superscript letters indicate significant differences $(p<0.05)$ between MRT measures and SF within columns, superscript numbers indicate differences of MRT within species, asterisks indicate significant differences in the respective value between $C$. bactrianus and $C$. dromedarius, while askterisks in brackets indicate trends

n.m. not measured, $M R T$ mean retention time, $F S$ forestomach, $S F$ selectivity factor
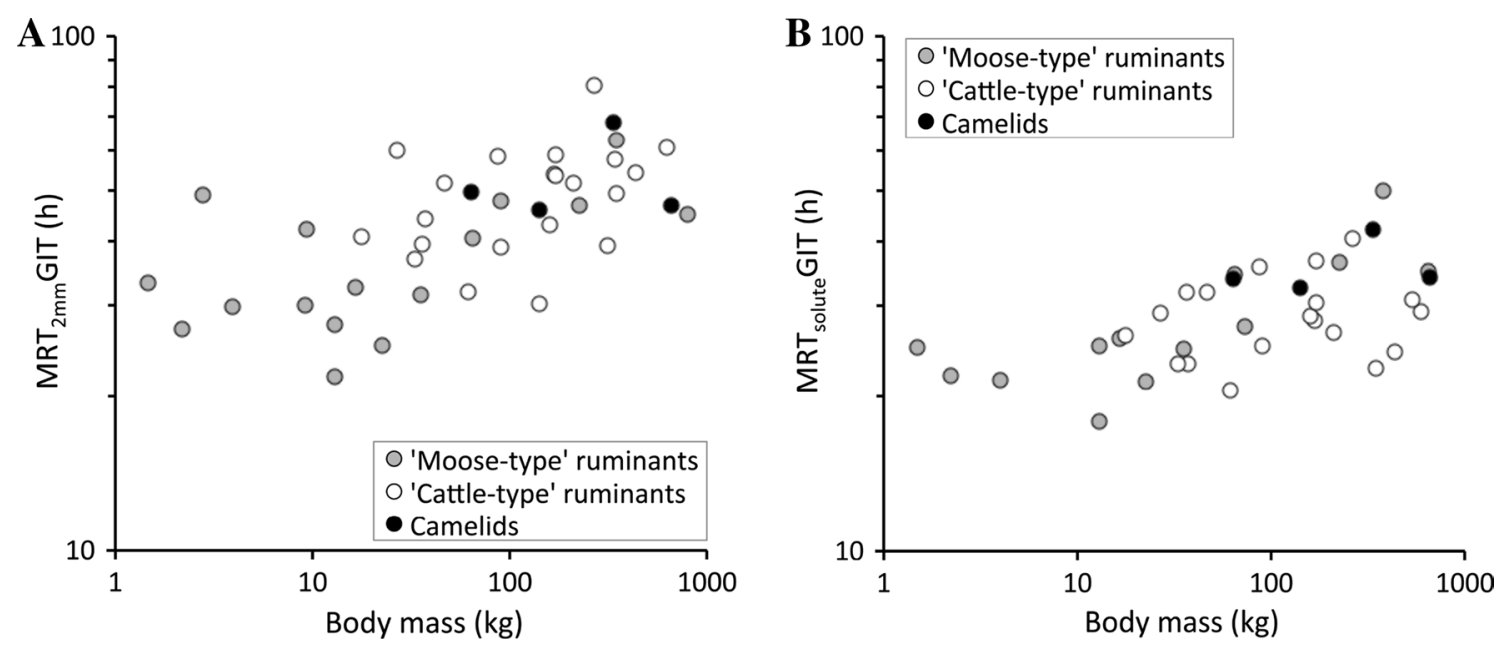

Fig. 3 Relationships of a the mean retention time of $2 \mathrm{~mm}$ particles in the gastrointestinal tract $\left(\mathrm{MRT}_{2 \mathrm{~mm}} \mathrm{GIT}\right)$ and $\mathbf{b}$ the mean retention time of

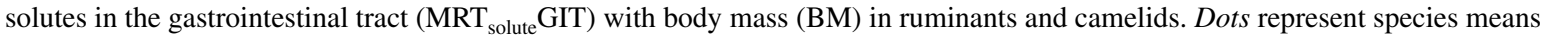

$(P=0.62)$. The SFs in the GIT were similar in the two camel species $\left(\mathrm{SF}_{2 \mathrm{~mm} / \text { solute }} \mathrm{GIT}: P=0.73 ; \mathrm{SF}_{20 / 2 \mathrm{~mm}} \mathrm{GIT}\right.$ : $P=0.99$ ), whereas $\mathrm{SF}_{2 \mathrm{~mm} / \text { solute }} \mathrm{FS}$ and $\mathrm{SF}_{20 / 2 \mathrm{~mm}} \mathrm{FS}$ were each higher in dromedaries than in Bactrian camels (both $P<0.001)$.

\section{Comparisons with literature data from ruminants: absolute MRTs}

When relating combined data from ruminants and camelids on $\mathrm{MRT}_{2 \mathrm{~mm}}$ and $\mathrm{MRT}_{\text {solute }}$, both for GIT and FS, to body mass, there were no significant interactions $(P>0.37)$ between herbivore type and BM. There were no significant differences $(P=0.10-0.94)$ between camelids and ruminants, or between camelids, 'cattle-' and 'moose-type' ruminants in these models. Camelid values were within the range reported for ruminants (Fig. 3). $\mathrm{MRT}_{2 \mathrm{~mm}} \mathrm{GIT}$ and FS, and $\mathrm{MRT}_{\text {solute }} \mathrm{GIT}$ were related to $\mathrm{BM}$ in GLS $\left(P<0.035\right.$; scaling exponents $\left.\mathrm{BM}^{0.07-0.12}[0.03 ; 0.20]\right)$ and
PGLS analyses $(P<0.001, \lambda=0.00$; scaling exponents $\left.\mathrm{BM}^{0.08-0.12[0.04 ; 0.19]}\right)$. $\mathrm{MRT}_{\text {solute }} \mathrm{FS}$ was not related to $\mathrm{BM}$ in GLS $(P=0.18)$ and tended towards significance in PGLS with a strong phylogenetic structure $(P=0.08 ; \lambda=0.92$; scaling exponent $\mathrm{BM}^{0.09}[-0.01 ; 0.18]$, indicating that closely related species have similar $\mathrm{MRT}_{\text {solute }} \mathrm{FS}$ values, independent of their BM.

\section{Comparison with literature data from ruminants: 'digesta washing' in the forestomach}

The $\mathrm{SF}_{2 \mathrm{~mm} / \text { solute }} \mathrm{FS}$ differed between ruminants and camelids $\left(\chi^{2}=125 ; P<0.001\right)$ with significantly lower values in 'moose-type' ruminants as compared with 'cattle-type' ruminants and camelids $(P<0.001)$ and a trend towards camelids being lower than 'cattle-type' ruminants $(P=0.084)$ (Fig. 4a). Correspondingly, a GLM with $\mathrm{MRT}_{2 \mathrm{~mm}} \mathrm{FS}$ as independent and $\mathrm{MRT}_{\text {solute }} \mathrm{FS}$ as dependent variable revealed significant influence of 


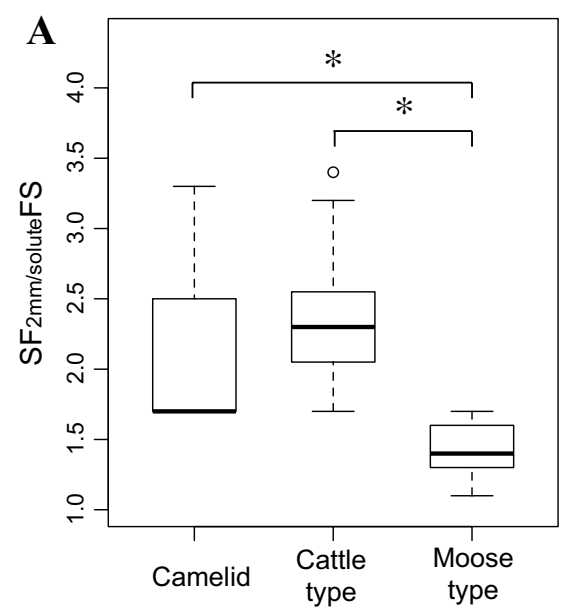

Fig. 4 a Comparison of the $\mathrm{SF}_{2 \mathrm{~mm} / \mathrm{solute}} \mathrm{FS}$ between species means from camelids and ruminats ('cattle-'or 'moose-type'). Boxplots indicate median, upper and lower quartile, as well as maximum and minimum values, dots indicate outliers and asterisks represent signifi-

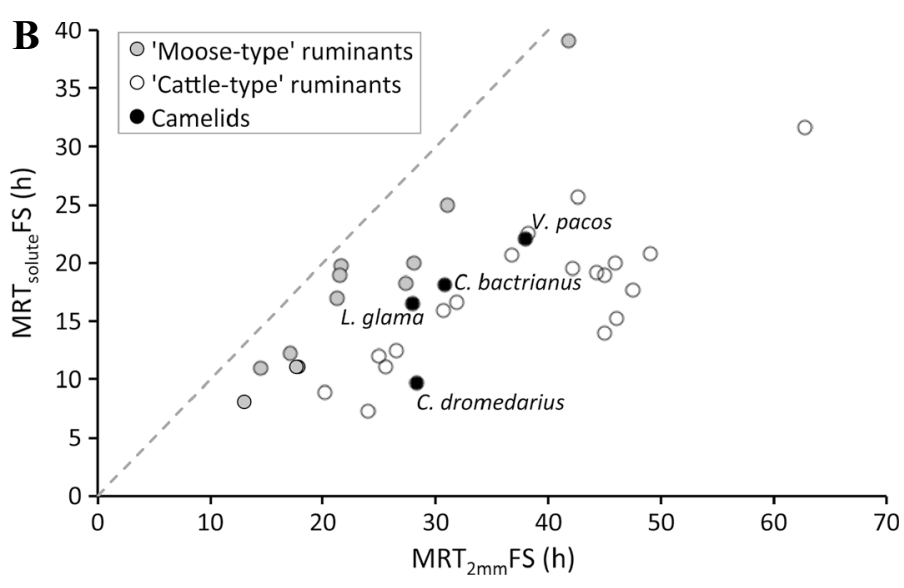

cant differences between herbivore types $(P<0.05)$. b Relationship between $\mathrm{MRT}_{\text {solute }} \mathrm{FS}$ and $\mathrm{MRT}_{2 \mathrm{~mm}} \mathrm{FS}$ in ruminants and camelids; dots represent species means; the dashed line represents equality of the two measures, i.e. an SF of 1

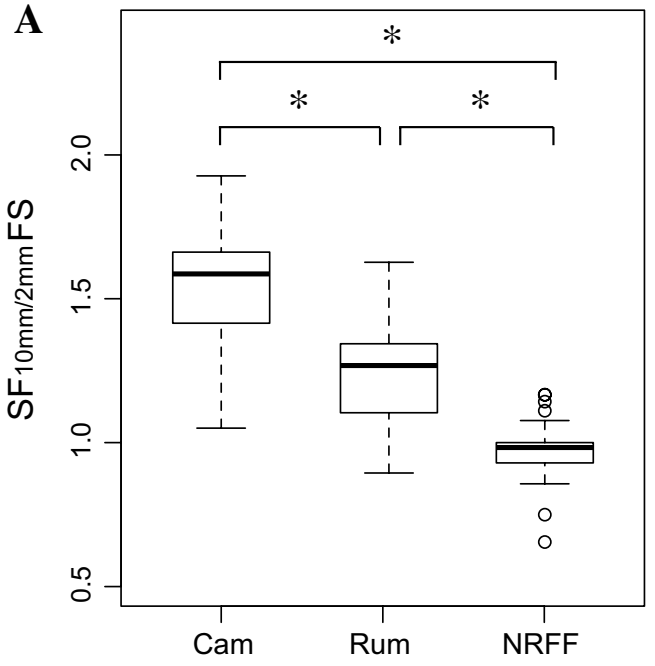

Fig. 5 a Comparison of individual data of the $\mathrm{SF}_{10 / 2 \mathrm{~mm}} \mathrm{FS}$ between camelids (Cam), Ruminants (Rum) and non-ruminant foregut fermenters (NRFF). b Relationship between $\mathrm{MRT}_{10 \mathrm{~mm}} \mathrm{FS}$ and $\mathrm{MRT}_{2 \mathrm{~mm}} \mathrm{FS}$

herbivore type $(P<0.001)$, with 'moose-type' ruminants having higher $\mathrm{MRT}_{\text {solute }} \mathrm{FS}$ than 'cattle-type' or camelids at a given $\mathrm{MRT}_{2 \mathrm{~mm}} \mathrm{FS}$ (Table 3 ; Fig. $4 \mathrm{~b}$ ). In a PGLS model with the same variables but without herbivore type as cofactor, there was a significant phylogenetic structure in the dataset $(\lambda=0.781)$, indicating similar values among closely related species. The fit of the GLS model with herbivore types was better than the PGLS model (AIC: -8.0 vs. 11.2). Note that the camelids do not achieve the very high $\mathrm{SF}_{2 \mathrm{~mm} / \text { solute }} \mathrm{FS}$ or short $\mathrm{MRT}_{\text {solute }} \mathrm{FS}$ of cattle or muskoxen (Ovibos moschatus) (Lechner et al. 2010).

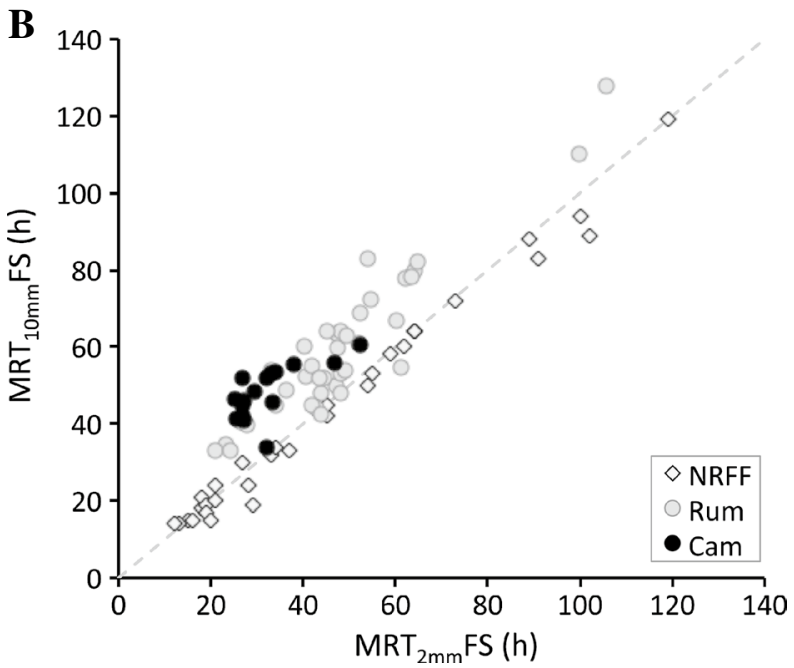

in the same herbivores; dots represent measurements of individuals; the dashed line represents equality of the two measures, i.e. an SF of 1

\section{Comparisons with literature data from ruminants and non-ruminant foregut fermenters: sorting mechanism}

The $\mathrm{SF}_{10 / 2 \mathrm{~mm}} \mathrm{GIT}$ and FS differed between ruminants, camelids, and NRFF $\left(\chi^{2}=52.9 / 52.8 ; P<0.001\right)$ with significantly lower values (close to equality) in NRFF as compared with ruminants and camelids $(P<0.001)$ and lower values in ruminants compared with camelids (GIT: $P=0.048$; FS: $P=0.029$; Fig. 5a). In a GLM with $\mathrm{MRT}_{2 \mathrm{~mm}} \mathrm{FS}$ as independent and $\mathrm{MRT}_{10 \mathrm{~mm}} \mathrm{FS}$ as dependent variable, there was a significant interaction with herbivore 
type, irrespective of whether NRFF were included in the analyses $(P<0.001)$ or not $(P=0.03)$ (Table 4$)$. While the significant interaction does not allow interpreting the exclusive effect of herbivore type in this relationship, the data analysis confirms that there is no particle sorting in NRFF and that camelids are generally within the higher range of ruminants (Fig. 5b).

More data could be included in the comparison of $\mathrm{SF}_{20 / 2 \mathrm{~mm}} \mathrm{FS}$ between herbivore types than for $\mathrm{SF}_{10 / 2 \mathrm{~mm}} \mathrm{FS}$ ( $n=102$ vs. 85 datapoints), but no data from NRFF were available for $\mathrm{SF}_{20 / 2 \mathrm{~mm}} \mathrm{FS}$. The $\mathrm{SF}_{20 / 2 \mathrm{~mm}} \mathrm{FS}$ was lower in ruminants than in camelids $(\mathrm{T}=4.5 ; P<0.001$; Fig. $6 \mathrm{a})$. Again, in a GLS with $\mathrm{MRT}_{2 \mathrm{~mm}} \mathrm{FS}$ as independent and $\mathrm{MRT}_{20 \mathrm{~mm}} \mathrm{FS}$ as dependent variable, there was a significant interaction with herbivore type $(P=0.001)$. The data indicate that camelids are generally within the higher range of ruminants in this relationship (Fig. 6b).

In contrast, the $\mathrm{SF}_{20 / 10 \mathrm{~mm}}$ GIT and FS did not differ between ruminants and camelids ( $\mathrm{W}=178 / 177$; $P=0.49 / 0.47$ ) and was close to equality (Fig. 7a). Also, in a GLS with $\mathrm{MRT}_{20 \mathrm{~mm}} \mathrm{FS}$ as independent and $\mathrm{MRT}_{10 \mathrm{~mm}} \mathrm{FS}$ as dependent variable, there was no difference between camelids and ruminants $(P=0.63)$ (Fig. 7b).

In GLS models with $\mathrm{SF}_{10 / 2 \mathrm{~mm}} \mathrm{FS}$ or $\mathrm{SF}_{20 / 2 \mathrm{~mm}} \mathrm{FS}$ as independent variable and rDMI as dependent variable, the latter was not significant $(P>0.10)$, while there was again a significant difference between ruminants and camelids $(P<0.001)$, indicating generally higher values in camelids compared with ruminants, independent of food intake. Applying the same model for $\mathrm{SF}_{20 / 10 \mathrm{~mm}} \mathrm{FS}$ revealed again no influence of $\mathrm{rDMI}(P=0.22)$, but no difference between ruminants and camelids $(P=0.67)$. There were no significant interactions between $\mathrm{rDMI}$ and herbivore type in these models $(P>0.11)$. Note that the ranges of rDMI were overlapping for camelids and ruminants, but the range of rDMI data of the camelids were less broad (27-44 $\mathrm{g} \mathrm{kg}$ $\left.\mathrm{BM}^{-0.85} \mathrm{~d}^{-1}\right)$ than the range of rDMI values from ruminants $\left(8-107 \mathrm{~g} \mathrm{~kg} \mathrm{BM}^{-0.85} \mathrm{~d}^{-1}\right)$.

\section{Discussion}

\section{Differences between camelid species}

In general, the absolute MRTs obtained from the camelids investigated in the present study do not confirm the particularly long retention times measured in other studies. For example, in Bactrian camels the MRTs measured in the GIT by Cahill and McBride (1995) were 50-80\% longer than the ones measured in the present study (MRT $_{\text {solute }}$ GIT: 50 vs. $34 \mathrm{~h}$; MRT $_{2 \mathrm{~mm}}$ GIT: 85 vs. $47 \mathrm{~h}$ ). In the llamas, $\mathrm{MRT}_{\text {solute }}$ GIT and $\mathrm{MRT}_{2 \mathrm{~mm}}$ GIT data from Heller et al. (1986a) exceeded the ones measured in the

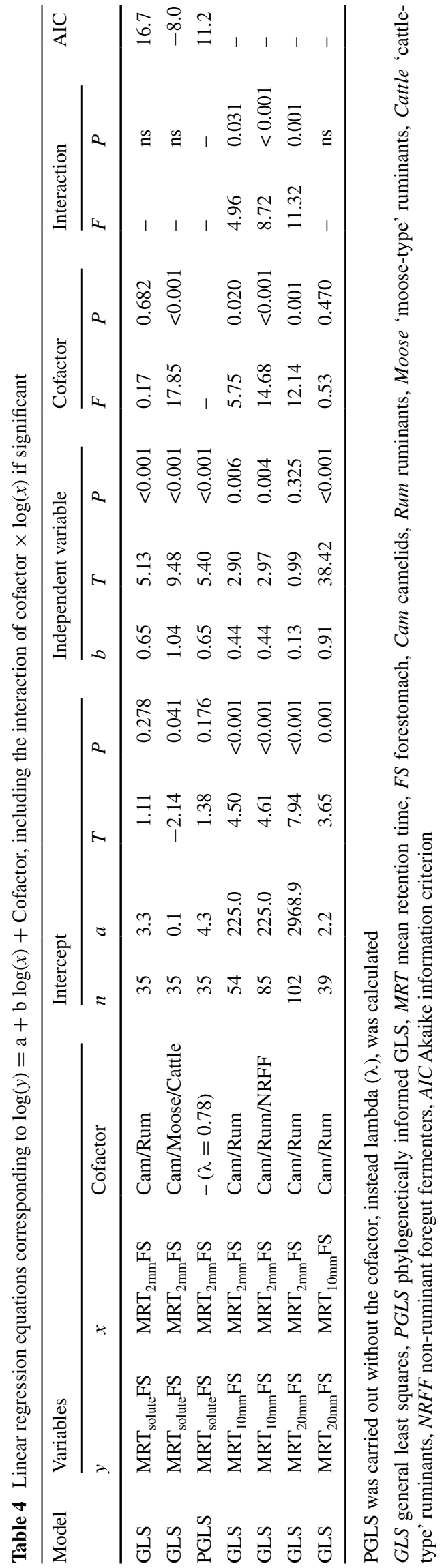




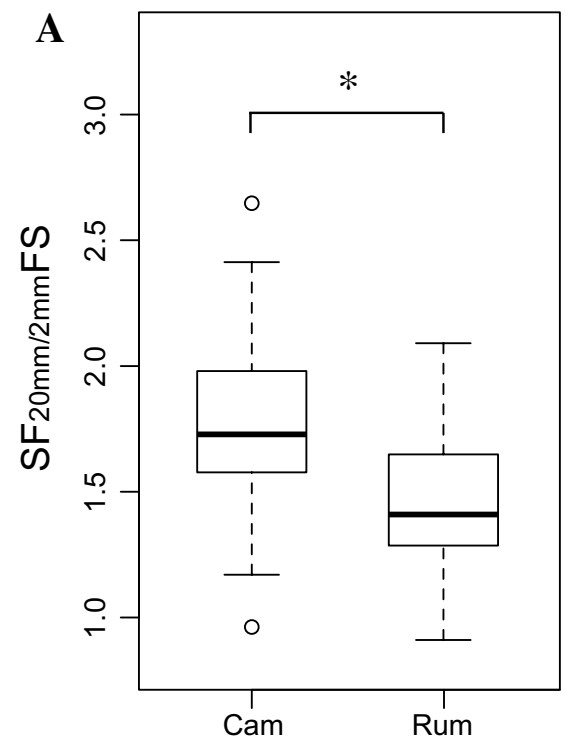

Fig. 6 a Comparison of individual data of the $\mathrm{SF}_{20 / 2 \mathrm{~mm}} \mathrm{FS}$ between camelids (Cam) and ruminants (Rum). b Relationship between $\mathrm{MRT}_{20 \mathrm{~mm}} \mathrm{FS}$ and $\mathrm{MRT}_{2 \mathrm{~mm}} \mathrm{FS}$ in ruminants and camelids; dots repre-

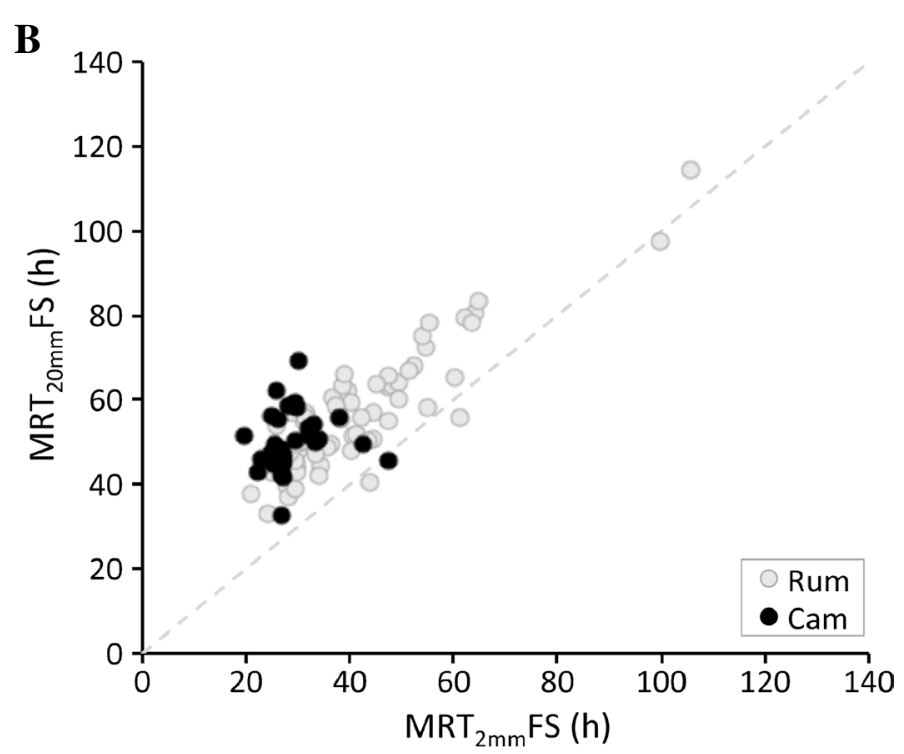

sent measurements of individuals; the dashed line represents equality of the two measures, i.e. an SF of 1

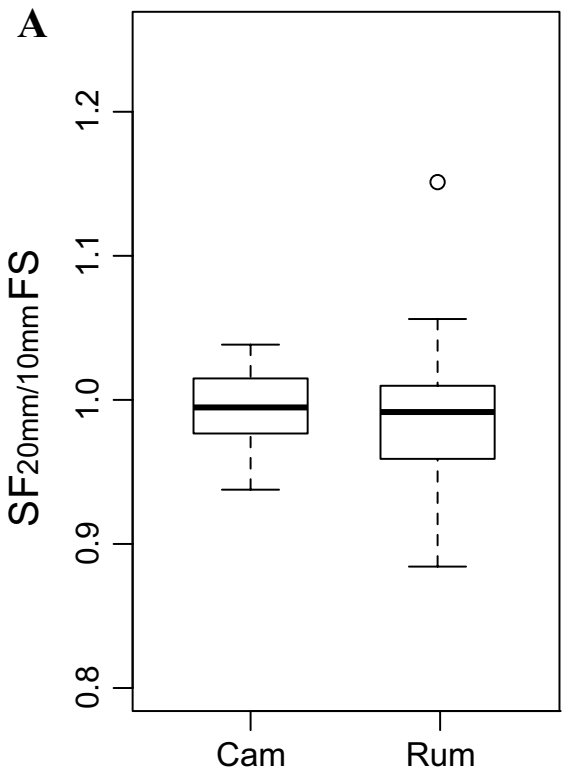

Fig. 7 a Comparison of individual data of the $\mathrm{SF}_{20 / 10 \mathrm{~mm}} \mathrm{FS}$ between camelids (Cam) and ruminants (Rum). b Relationship between $\mathrm{MRT}_{20 \mathrm{~mm}} \mathrm{FS}$ and $\mathrm{MRT}_{10 \mathrm{~mm}} \mathrm{FS}$ in ruminants and camelids; dots repre-

present study by approximately $30 \%$. These differences might well be explained by differences in the food intake level, as described for Bactrian camels by Cahill and McBride (1995), which influence MRT within and across species (Müller et al. 2013; Clauss et al. 2014). Therefore, measurements of retention time should ideally always be

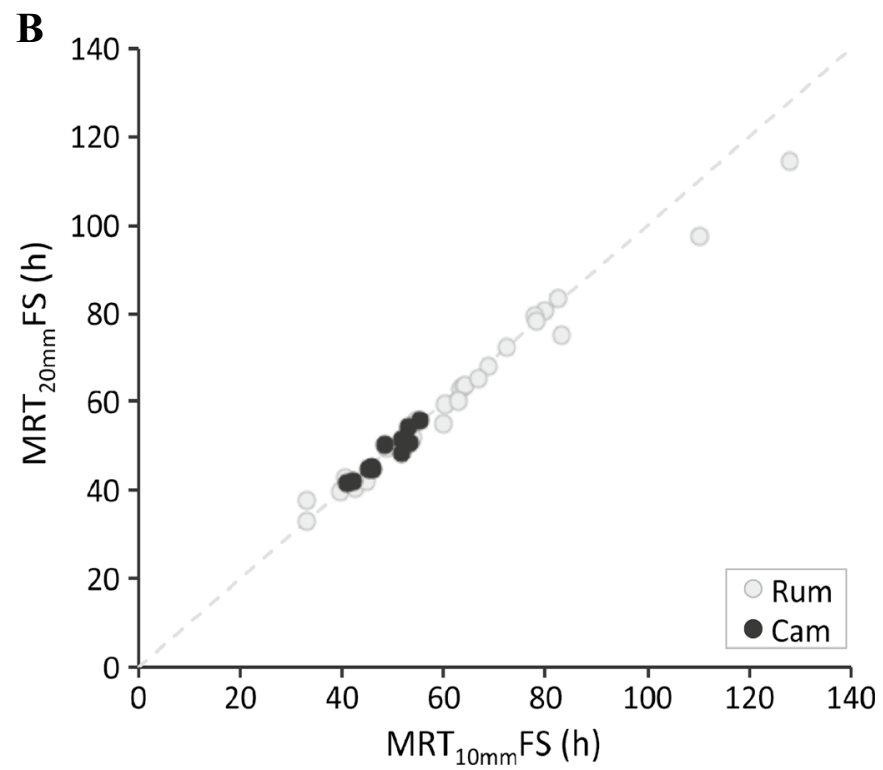

sent measurements of individuals; the dashed line represents equality of the two measures, i.e. an SF of 1

accompanied by assessments of intake, and conclusions made from comparisons of absolute MRTs must account for the effect of food intake (Levey and Martínez del Rio 1999).

It would have been preferable to also include dromedaries into the experiment and feed them the same 
lucerne-based diet, but this was not possible due to a lack of available animals. No data on food intake or $\mathrm{MRT}_{10 \mathrm{~mm}}$ were available for dromedaries in the literature, which is why dromedaries could not be included in the statistical comparisons between herbivores with respect to this marker. Generally, dromedary data from Lechner-Doll et al. (1990) indicated longer retention times in the GIT compared with Bactrian camels. Dromedaries had relatively short $\mathrm{MRT}_{\text {solute }} \mathrm{FS}$ of $11 \pm 1 \mathrm{~h}$ compared with $19 \pm 3 \mathrm{~h}$ in Bactrian camels and also shorter $\mathrm{MRT}_{\text {solute }} \mathrm{FS}$ than the smaller species investigated in this study. $\mathrm{MRT}_{\text {particle }} \mathrm{FS}$ were similar in dromedaries when compared with the camelids investigated in this study, which resulted in comparably higher SF values in the FS of dromedaries (also documented by Heller et al. 1986c). Other measurements reported for tulus (hybrids of C. bactrianus and C. dromedarius) under hydrated conditions indicated short $\mathrm{MRT}_{\text {solute }} \mathrm{FS}$ of $12 \mathrm{~h}$ (von Engelhardt et al. 2006b), similar to the $\mathrm{MRT}_{\text {solute }} \mathrm{FS}$ in the dromedaries. Contrasting to the short $\mathrm{MRT}_{\text {solute }} \mathrm{FS}$ found in the camelids, long $\mathrm{MRT}_{\text {solute }} \mathrm{FS}$ in ruminants have been interpreted as a consequence of a proportionately large FS that serves as a water storage organ (Silanikove 1994; Hummel et al. 2008). Dromedaries, with a comparatively smaller proportionate FS volume than ruminants (Lechner-Doll et al. 1990), apparently do not use the FS to the same extent as a water reservoir. Actually, even after severe dehydration and a sudden re-hydration, the camelid FS does not maintain an enlarged volume for more than 1 day (von Engelhardt et al. 2006b). Therefore, the camelids' adaptation to water shortage appears to consist in their ability to rapidly ingest large amounts of water when it is available, and to absorb this water quickly into the body, rather than retain it in the FS (von Engelhardt et al. 2006b), as for example observed in the desert-adapted addax antelope (Addax nasomaculatus) (Hummel et al. 2008).

\section{Comparing digesta washing between camelids and ruminants}

Digesta washing can be described by the difference between the MRT $\mathrm{Marticle}_{\text {and the }} \mathrm{MRT}_{\text {solute }}$, expressed as the ratio of the two measures, the SF. In the case of high ratios, a faster-moving fluid phase washes through a slowermoving particulate digesta phase, thereby removing solutes and very fine particles, including microbes, from this plug (Lentle et al. 2006; Müller et al. 2011). This process is not restricted to ruminants as it can also be found in some NRFF and other digestion types (Müller et al. 2011). Within ruminants, species differ in rumen fluid throughput and the degree of digesta washing (Clauss and LechnerDoll 2001; Clauss et al. 2006; Dittmann et al. 2015; Hummel et al. 2015), which led to the classification of 'cattle-' and 'moose-type' ruminants. Therefore, the finding that 'cattle-' and 'moose-type' ruminants differ significantly in the $\mathrm{SF}_{2 \mathrm{~mm} / \mathrm{solute}} \mathrm{FS}$ (Fig. 4a) is no surprise because the measure is actually used for the classification. Therefore, it appears that camelids in general have evolved a 'cattletype' strategy, although guanacos (Lama guanicoe) and vicuñas (Vicugna vicugna) have not yet been subjected to digesta retention measurements.

The proposed major advantage of the 'cattle-type' strategy is an increased harvest of microbes from the FS, leading to a higher general yield of microbial protein, and selection for a fast-growing and particularly efficient microbial community in the FS (Clauss et al. 2010; Dittmann et al. 2015; Hummel et al. 2015). Due to this higher microbial yield, the 'cattle-type' strategy might be particularly suitable for camelids with their greater ability to recycle urea as compared with domestic ruminants (Hinderer and von Engelhardt 1975; von Engelhardt and Schneider 1977). The 'moose-type' strategy has been linked with browse feeding and salivary defences against tannins (Hofmann et al. 2008; Codron and Clauss 2010). Because browse often represents the main component of the diet of free-ranging dromedaries (reviewed in Iqbal and Khan 2001), the 'cattle-type' dromedaries must have evolved alternative strategies to deal with tannins that are not related to saliva viscosity.

Considering only ruminants, the 'moose-type' strategy is prominent in basal groups such as the tragulids or giraffids (Clauss and Lechner-Doll 2001; Hummel et al. 2005; Darlis et al. 2012) and could, therefore, appear as the basal physiological strategy of the ruminant suborder. However, the high $\mathrm{SF}_{2 \mathrm{~mm} / \mathrm{solute}} \mathrm{FS}$ in the more distantly related camelids could allow the interpretation that a higher degree of digesta washing as in 'cattle-type' ruminants represents the basal situation, and that the 'moose-type' strategy may be a more derived state. Although some evidence matches the latter hypothesis, e.g. the observation of the 'moose-type' strategy in the subfamily of the Cephalophines (Clauss et al. 2011) or in dikdik (Madoqua spp.) (Hebel et al. 2011), which are considered derived ecomorphs (Bärmann 2014), more measurements in a larger number of species are required to confirm this concept.

\section{Comparing particle sorting in camelids, ruminants, and non-ruminant foregutfermenters}

The sorting of large vs. small particles is crucial for the process of rumination, as it ensures that only those particles that can be efficiently further reduced in size are subjected to repeated mastication (Lauper et al. 2013). However, the actual sorting is rather based on particle density than on particle size (Baumont and Deswysen 1991; Lechner-Doll et al. 1991), because larger particles typically have a lower functional density and hence a propensity to float in a liquid medium (Sutherland 1988; Clauss et al. 2009b). In the 
FS of ruminants, there is a clear distinction between the reticulorumen on the one hand, where particles of all sizes occur, and the omasum on the other hand, where only small particles are present (Clauss et al. 2009a, b). This means that the orifice between the reticulum and the omasum is a point of demarcation. In the FS of the camelids, however, this separation is somewhat less distinct. Although there is also a clear difference in particle sizes present between compartments $\mathrm{C} 1 / \mathrm{C} 2$ (corresponding to the reticulorumen) and the distal part of $\mathrm{C} 3 /$ hindstomach (corresponding to the abomasum), there apparently is a more gradual transition within the proximal part of the $\mathrm{C} 3$ compartment, where not as many large particles as in $\mathrm{C} 1 / \mathrm{C} 2$, but still more than those in the distal C3, are present (Lechner-Doll and von Engelhardt 1989). This suggests that the orifice between C2 and $\mathrm{C} 3$, although similar in its width to that of the orifice between the reticulum and omasum in ruminants (Langer 1988), may not represent an absolute demarcation point in camelids. The similar, comparatively low faecal particle sizes in ruminants and camelids (Fritz et al. 2009) leads to the assumption that the large particles in $\mathrm{C} 3$ must be transferred back to the more proximal parts of the FS to be ruminated and thereby eventually reduced in size.

Comparing the findings on the retention of differentsized particles in camelids with those from ruminants reveals several similarities. The marker excretion curves recorded in the present study are generally similar to those found in ruminants (compare for example, our camelid Fig. 2 to the excretion curves shown in Schwarm et al. 2008 or Lechner et al. 2010). As previously found in ruminants, camelids also do not discriminate between particles of 10 or $20 \mathrm{~mm}$. In ruminants this pattern is independent of whether the markers are fed directly to the animal (Schwarm et al. 2009a) or inserted into the rumen via fistula (Lechner et al. 2010). In other words, this pattern is not affected by ingestive mastication. Therefore, it appears unlikely that the lack of discrimination between these sizes is due to the method of marker application in the present study, i.e. that large particle markers had been significantly reduced in size by mastication before they reached the FS. Evidently, within species for which such data are available (llamas, Bactrian camels, reindeer, muskoxen, moose, and cattle), particle size has no additional influence on particle retention above a certain threshold of about $1 \mathrm{~cm}$. Whether a similar threshold exists in smaller species remains to be investigated.

The present comparison of relationships of large to small particle retention between camelids, ruminants, and NRFF suggests that a sorting mechanism sets ruminants and camelids apart from other foregut fermenters (Fig. 5) and represents, given the distant relatedness of camelids and ruminants, a convergent adaptation where the same function is achieved by different morphophysiological designs. This convergence not only manifests in patterns of MRT (present study), FS motility and chewing activity (Heller et al. 1986b; von Engelhardt et al. 2006a), but also in particle size reduction (Fritz et al. 2009) and the high fibre-digestibility when compared with other NRFF (Hintz et al. 1973; Sponheimer et al. 2003; Clauss et al. 2009c; Steuer et al. 2013).

The results of the present study indicate a quantitative difference in the sorting of large vs. small particles between herbivore types, with longer $10 \mathrm{~mm}$ or $20 \mathrm{~mm}$ to $2 \mathrm{~mm}$ particle retention in camelids as compared with ruminants (and NRFF), evident as higher $\mathrm{SF}_{10 \mathrm{~mm} / 2 \mathrm{~mm}} \mathrm{FS}$ and $\mathrm{SF}_{20 \mathrm{~mm} / 2 \mathrm{~mm}} \mathrm{FS}$ (Figs. 5, 6). These higher SF values appear to be caused by a longer retention of large particles rather than a shorter retention of $2 \mathrm{~mm}$ particles. The difference between ruminants and camelids was not explained by differences in food intake level and hence might reflect true functional differences between the morphophysiological designs of the ruminant and the camelid FS. Whether longer retention of large particles could explain the observation that, under similar experimental conditions, camelids usually have a lower food intake than ruminants (Meyer et al. 2010; Dittmann et al. 2014a) and a generally lower level of metabolism (Dittmann et al. 2014a) remains speculative. Interpreting the effects of morphophysiological characteristics of the GIT as constraint for other physiological functions, and ultimately for the competitiveness and diversity of taxonomic groups, could lead to instructive narratives (e.g. Janis et al. 1994; Clauss and Rössner 2014). In the case of camelids, both more functional measurements, such as particle size distributions in the different FS compartments, and a systematic evaluation of the fossil record in comparison to ruminants, are necessary to support such a narrative.

\section{Conclusion}

The results of this study indicate a distinct convergence between camelids and ruminants in terms of the presence of a particle sorting mechanism in their digestive tracts, as well as in the degree of 'digesta washing' between camelids and 'cattle-type' ruminants. They also provide preliminary evidence that the particle sorting mechanism differs in detail between the two groups. To explore this putative difference, more detailed studies on the retention mechanism are required.

Acknowledgments We thank Jörg Wick, Andreas Thalmann and the animal keeper team of Zurich Zoo and the entire team of the Kamelhof Olmerswil for their support during animal management. We are also grateful to Catharina Vendl and Walter Salzburger for their help during the sampling period, Simon Ineichen for sample preparation, and Heidrun Barleben, Carmen Kunz, Muna Merghani and 
Elisabeth Wenk for sample analysis. This study was part of project 310030_135252/1 funded by the Swiss National Science Foundation.

\section{References}

AOAC (1995) Official methods of analysis of AOAC International. Association of Official Analytical Chemists, Arlington VA

Barker S, Brown GD, Calaby JH (1963) Food regurgitation in the macropodidae. Aust J Sci 25:430-432

Bärmann EV (2014) The evolution of body size, horn shape and social behaviour in crown Antilopini-an ancestral character state analysis. Zitteliana B 32:185-196

Bauchop T, Martucci RW (1968) Ruminant-like digestion of the langur monkey. Science 161:698-700

Baumont R, Deswysen AG (1991) Mélange et propulsion du contenu du réticulo-rumen. Repr Nutr Dev 31:335-359

Blaxter KL, Graham NM, Wainman FW (1956) Some observations on the digestibility of food by sheep, and on related problems. Br J Nutr 10:69-91

Bruining M, Bosch MW (1992) Ruminal passage rate as affected by CrNDF particle size. Anim Feed Sci Technol 37:193-200

Cahill LW, McBride BW (1995) Effect of level of intake on digestion, rate of passage and chewing dynamics in hay-fed Bactrian camels. Proc Nutr Adv Group 1:3-35

Clauss M, Lechner-Doll M (2001) Differences in selective reticuloruminal particle retention as a key factor in ruminant diversification. Oecologia 129:321-327

Clauss M, Rössner GE (2014) Old world ruminant morphophysiology, life history, and fossil record: exploring key innovations of a diversification sequence. Ann Zool Fenn 51:80-94

Clauss M, Schwarm A, Ortmann S, Alber D, Flach EJ, Kühne R, Hummel J, Streich WJ, Hofer H (2004) Intake, ingesta retention, particle size distribution and digestibility in the hippopotamidae. Comp Biochem Physiol A 139:449-459

Clauss M, Hummel J, Streich WJ (2006) The dissociation of the fluid and particle phase in the forestomach as a physiological characteristic of large grazing ruminants: an evaluation of available, comparable ruminant passage data. Eur J Wildl Res 52:88-98

Clauss M, Fritz J, Bayer D, Hummel J, Streich WJ, Südekum K-H, Hatt J-M (2009a) Physical characteristics of rumen contents in two small ruminants of different feeding type, the mouflon (Ovis ammon musimon) and the roe deer (Capreolus capreolus). Zoology 112:195-205

Clauss M, Fritz J, Bayer D, Nygren K, Hammer S, Hatt J-M, Südekum K-H, Hummel J (2009b) Physical characteristics of rumen contents in four large ruminants of different feeding type, the addax (Addax nasomaculatus), bison (Bison bison), red deer (Cervus elaphus) and moose (Alces alces). Comp Biochem Physiol A 152:398-406

Clauss M, Nunn C, Fritz J, Hummel J (2009c) Evidence for a tradeoff between retention time and chewing efficiency in large mammalian herbivores. Comp Biochem Physiol A 154:376-382

Clauss M, Hume ID, Hummel J (2010) Evolutionary adaptations of ruminants and their potential relevance for modern production systems. Animal 4:979-992

Clauss M, Lunt N, Ortmann S, Plowman A, Codron D, Hummel J (2011) Fluid and particle passage in three duiker species. Eur J Wildl Res 57:143-148

Clauss M, Schiele K, Ortmann S, Fritz J, Codron D, Hummel J, Kienzle E (2014) The effect of very low food intake on digestive physiology and forage digestibility in horses. J Anim Physiol Anim Nutr 98:107-118

Codron D, Clauss M (2010) Rumen physiology constrains diet niche: linking digestive physiology and food selection across wild ruminant species. Can J Zool 88:1129-1138
Darlis NA, Liang JB, Ho YW (2012) Effects of diets of differing fiber contents on digestibility, passage rate of digesta and heat production in lesser mouse deer (Tragulus javanicus). Mamm Biol 77:385-390

Development Core Team R (2012) R: a language and environment for statistical computing. R Foundation for Statistical Computing, Vienna

Dittmann MT, Hummel J, Runge U, Galeffi C, Kreuzer M, Clauss M (2014a) Characterising an artiodactyl family inhabiting arid habitats by its metabolism: low metabolism and maintenance requirements in camelids. J Arid Environ 107:41-48

Dittmann MT, Runge U, Lang RA, Moser D, Galeffi C, Kreuzer M, Clauss M (2014b) Methane emission by camelids. PLoS ONE 9:e94363

Dittmann MT, Hummel J, Hammer S, Arif A, Hebel C, Müller DHW, Fritz J, Steuer P, Schwarm A, Kreuzer M, Clauss M (2015) Digesta retention in gazelles in comparison to other ruminants: evidence for taxon-specific rumen fluid throughput to adjust digesta washing to the natural diet. Comp Biochem Physiol A 185:58-68

Felsenstein J (1985) Phylogenies and the comparative method. Am Nat 125:1-15

Frei S, Ortmann S, Reutlinger C, Kreuzer M, Hatt J-M, Clauss M (2015) Comparative digesta retention patterns in ratites. Auk Ornithol Adv 132:119-131

Fritz J, Hummel J, Kienzle E, Arnold C, Nunn C, Clauss M (2009) Comparative chewing efficiency in mammalian herbivores. Oikos 118:1623-1632

Gordon JG (1968) Rumination and its significance. Wrld Rev Nutr Diet 9:251-273

Grovum WL, Williams VJ (1973) Rate of passage of digesta in sheep: 4. Passage of marker through the alimentary tract and the biological relevance of rate-constants derived from the changes in concentration of marker in faeces. Br J Nutr 30:313-329

Hebel C, Ortmann S, Hammer S, Hammer C, Fritz J, Hummel J, Clauss M (2011) Solute and particle retention in the digestive tract of the Phillip's dikdik (Madoqua saltiana phillipsi), a very small browsing ruminant: biological and methodological implications. Comp Biochem Physiol A 159:284-290

Heller R, Gregory PC, von Engelhardt W (1984) Pattern of motility and flow of digesta in the forestomach of the llama (Lama guanacoe f. glama). J Comp Physiol B 154:529-533

Heller R, Cercasov V, von Engelhardt W (1986a) Retention of fluid and particles in the digestive tract of the llama (Lama guanacoe f. glama). Comp Biochem Physiol A 83:687-691

Heller R, Lechner M, von Engelhardt W (1986b) Forestomach motility in the camel (Camelus dromedarius). Comp Biochem Physiol A 84:285-288

Heller R, Lechner M, Weyreter H, von Engelhardt W (1986c) Forestomach fluid volume and retention time of fluid and particles in the gastrointestinal tract of the camel (Camelus dromedarius). $\mathrm{J}$ Vet Med A 33:396-399

Hendrichs H (1965) Vergleichende Untersuchung des Wiederkauverhaltens. Biol Zentrbl 84:681-751

Hinderer S, von Engelhardt W (1975) Urea metabolism in the llama. Comp Biochem Physiol A 52:619-622

Hintz HF, Schryver HF, Halbert M (1973) A note on the comparsion of digestion by new world camels, sheep and ponies. Anim Prod 16:303-305

Hofmann RR, Streich WJ, Fickel J, Hummel J, Clauss M (2008) Convergent evolution in feeding types: salivary gland mass differences in wild ruminant species. J Morphol 269:240-257

Hummel J, Clauss M, Zimmermann W, Johanson K, Norgaard C, Pfeffer E (2005) Fluid and particle retention in captive okapi (Okapia johnstoni). Comp Biochem Physiol A 140:436-444 
Hummel J, Steuer P, Südekum K-H, Hammer S, Hammer C, Streich WJ, Clauss M (2008) Fluid and particle retention in the digestive tract of the addax antelope (Addax nasomaculatus) - adaptations of a grazing desert ruminant. Comp Biochem Physiol A 149:142-149

Hummel J, Hammer S, Hammer C, Ruf J, Lechenne M, Clauss M (2015) Solute and particle retention in a small grazing antelope, the blackbuck (Antilope cervicapra). Comp Biochem Physiol A 182:22-26

Hungate RE (1966) The rumen and its microbes. Academic Press, London

Iqbal A, Khan BB (2001) Feeding behaviour of camel, Review. Pakistan J Agric Sci 38:58-63

Janis CM, Gordon IJ, Illius AW (1994) Modelling equid/ruminant competition in the fossil record. Hist Biol 8:15-29

Kaske M, Groth A (1997) Changes in factors affecting the rate of digesta passage through pregnancy and lactation in sheep fed on hay. Repr Nutr Dev 37:573-588

Langer P (1988) The mammalian herbivore stomach. Gustav Fischer, Stuttgart

Lauper M, Lechner I, Barboza P, Collins W, Hummel J, Codron D, Clauss M (2013) Rumination of different-sized particles in muskoxen (Ovibos moschatus) and moose (Alces alces) on grass and browse diets, and implications for rumination in different ruminant feeding types. Mamm Biol 78:142-152

Lechner I, Barboza P, Collins W, Fritz J, Günther D, Hattendorf B, Hummel J, Südekum K-H, Clauss M (2010) Differential passage of fluids and different-sized particles in fistulated oxen (Bos primigenius f. taurus), muskoxen (Ovibos moschatus), reindeer (Rangifer tarandus) and moose (Alces alces): rumen particle size discrimination is independent from contents stratification. Comp Biochem Physiol A 155:211-222

Lechner-Doll M, von Engelhardt W (1989) Particle size and passage from the forestomach in camels compared to cattle and sheep fed a similar diet. J Anim Physiol Anim Nutr 61:120-128

Lechner-Doll M, Rutagwenda T, Schwartz HJ, Schultka W, von Engelhardt W (1990) Seasonal changes of ingesta mean retention time and forestomach fluid volume in indigenous camels, cattle, sheep and goats grazing in a thornbush savanna pasture in Kenya. J Agric Sci 115:409-420

Lechner-Doll M, Kaske M, von Engelhardt W (1991) Factors affecting the mean retention time of particles in the forestomach of ruminants and camelids. In: Tsuda T, Sasaki Y, Kawashima R (eds) Physiological aspects of digestion and metabolism in ruminants. Academic Press, San Diego, pp 455-482

Lechner-Doll M, von Engelhardt W, Abbas HM, Mousa L, Luciano L, Reale E (1995) Particularities in forestomach anatomy, physiology and biochemistry of camelids compared to ruminants. In: Tisserand JL (ed) Elevage et alimentation du dromadaire-Camel production and nutrition Options méditerranéennes, Serie B. Etudes et Recherches Nr. 13 CIHEAM, Paris, pp 19-32

Lentle R, Hemar Y, Hall C (2006) Viscoelastic behaviour aids extrusion from and reabsorption of the liquid phase into the digesta plug: creep rheometry of hindgut digesta in the common brushtail possum Trichosurus vulpecula. J Comp Physiol B 176:469-475

Levey D, Martínez del Rio C (1999) Test, rejection and reformulation of a chemical reactor-based model of gut function in a fruiteating bird. Physiol Biochem Zool 72:369-383

Lirette A, Milligan LP (1989) A quantitative model of reticulo-rumen particle degradation and passage. Br J Nutr 62:465-479

Logan M (2001) Evidence for the occurence of rumination-like behaviour, or merycism, in koalas (Phascolarctos cinereus). $\mathbf{J}$ Zool 255:83-87

Logan M (2003) Effect of tooth wear on the rumination-like behavior, or merycism, of free-ranging koalas (Phascolarctos cinereus). J Mammal 84:897-902
Lord RD (1994) A descriptive account of capybara behavior. Stud Neotrop Fauna Environ 29:11-22

Mambrini M, Peyraud JL (1997) Retention time of feed particles and liquids in the stomachs and intestines of dairy cows. Direct measurement and calculation based on fecal collection. Repr Nutr Dev 37:427-442

Matsuda I, Murai T, Clauss M, Yamada T, Tuuga A, Bernard H, Higashi S (2011) Regurgitation and remastication in the foregut-fermenting proboscis monkey (Nasalis larvatus). Biol Lett 7:786-789

Matsuda I, Tuuga A, Hashimoto C, Bernard H, Yamagiwa J, Fritz J, Tsubokawa K, Yayota M, Murai T, Iwata Y, Clauss M (2014) Faecal particle size in free-ranging primates supports 'rumination' strategy in the proboscis monkey (Nasalis larvatus). Oecologia 174:1127-1137

Meyer K, Hummel J, Clauss M (2010) The relationship between forage cell wall content and voluntary food intake in mammalian herbivores. Mammal Rev 40:221-245

Moir RJ, Somers M, Sharman G, Waring H (1954) Ruminant-like digestion in a marsupial. Nature 173:269-270

Moir RJ, Somers M, Waring H (1956) Studies on marsupial nutrition. I. Ruminant-like digestion in a herbivorous marsupial. Aust $\mathbf{J}$ Biol Sci 9:293-304

Mollison BC (1960) Food regurgitation in Bennett's wallaby and the scrub wallaby. CSIRO Wildl Res 5:87-88

Müller DWH, Caton J, Codron D, Schwarm A, Lentle R, Streich WJ, Hummel J, Clauss M (2011) Phylogenetic constraints on digesta separation: variation in fluid throughput in the digestive tract in mammalian herbivores. Comp Biochem Physiol A 160:207-220

Müller DWH, Codron D, Meloro C, Munn A, Schwarm A, Hummel J, Clauss M (2013) Assessing the Jarman-Bell Principle: scaling of intake, digestibility, retention time and gut fill with body mass in mammalian herbivores. Comp Biochem Physiol A 164:129-140

Schwarm A, Ortmann S, Wolf C, Streich WJ, Clauss M (2008) Excretion patterns of fluids and particle passage markers of different size in banteng (Bos javanicus) and pygmy hippopotamus (Hexaprotodon liberiensis): two functionally different foregut fermenters. Comp Biochem Physiol A 150:32-39

Schwarm A, Ortmann S, Wolf C, Clauss M (2009a) No distinct difference in the excretion of large particles of varying size in a wild ruminant, the banteng (Bos javanicus). Eur J Wildl Res 55:531-533

Schwarm A, Ortmann S, Wolf C, Streich WJ, Clauss M (2009b) More efficient mastication allows increasing intake without compromising digestibility or necessitating a larger gut: comparative feeding trials in banteng (Bos javanicus) and pygmy hippopotamus (Hexaprotodon liberiensis). Comp Biochem Physiol A 152:504-512

Schwarm A, Ortmann S, Wolf C, Streich WJ, Clauss M (2009c) Passage marker excretion in red kangaroo (Macropus rufus), collared peccary (Pecari tajacu) and colobine monkeys (Colobus angolensis, $C$. polykomos, Trachypithecus johnii). J Exp Zool A 311:647-661

Schwarm A, Ortmann S, Fritz J, Rietschel W, Flach EJ, Clauss M (2013) No distinct stratification of ingesta particles and no distinct moisture gradient in the forestomach of nonruminants: the wallaby, peccary, hippopotamus, and sloth. Mamm Biol 78:412-421

Silanikove N (1994) The struggle to maintain hydration and osmoregulation in animals experiencing severe dehydration and rapid rehydration: the story of ruminants. Exp Physiol 79:281-300

Sponheimer M, Robinson T, Roeder B, Hammer J, Ayliffe L, Passey B, Cerling T, Dearing D, Ehleringer J (2003) Digestion and passage rates of grass hay by llamas, alpacas, goats, rabbits and horses. Small Rum Res 48:149-154

Steuer P, Südekum K-H, Müller DWH, Kaandorp J, Clauss M, Hummel J (2013) Fibre digestibility in large herbivores as related to 
digestion type and body mass - an in vitro approach. Comp Biochem Physiol A 164:319-326

Sutherland TM (1988) Particle separation in the forestomach of sheep. In: Dobson A, Dobson MJ (eds) Aspects of digestive physiology in ruminants. Cornell University Press, Ithaca, pp 43-73

Thielemans MF, Francois E, Bodart C, Thewis A (1978) Mesure du transit gastrointestinal chez le porc a l'aide des radiolanthanides. Comparaison avec le mouton. Ann Biol Anim Biochim Biophys 18:237-247

Udén P, Colucci PE, Van Soest PJ (1980) Investigation of chromium, cerium and cobalt as markers in digesta. Rate of passage studies. J Sci Food Agric 31:625-632

Vallenas A, Cummings JF, Munnell JF (1971) A gross study of the compartmentalized stomach of two New-World camelids, the llama and guanaco. J Morphol 134:399-424

Van Weyenberg S, Sales J, Janssens GPJ (2006) Passage rate of digesta through the equine gastrointestinal tract: a review. Livestock Sci 99:3-12 von Engelhardt W, Schneider W (1977) Energy and nitrogen metabolism in the llama. Anim Res Dev 5:68-72

von Engelhardt W, Haarmeyer P, Kaske M, Lechner-Doll M (2006a) Chewing activities and oesophageal motility during feed intake, rumination and eructuation in camels. J Comp Physiol B 176:117-124

von Engelhardt W, Haarmeyer P, Lechner-Doll M (2006b) Feed intake, forestomach fluid volume, dilution rate and mean retention of fluid in the forestomach during water deprivation and rehydration in camels (Camelus sp.). Comp Biochem Physiol A 143:504-507

Warner ACI (1981) Rate of passage through the gut of mammals and birds. Nutr Abstr Rev B 51:789-820 